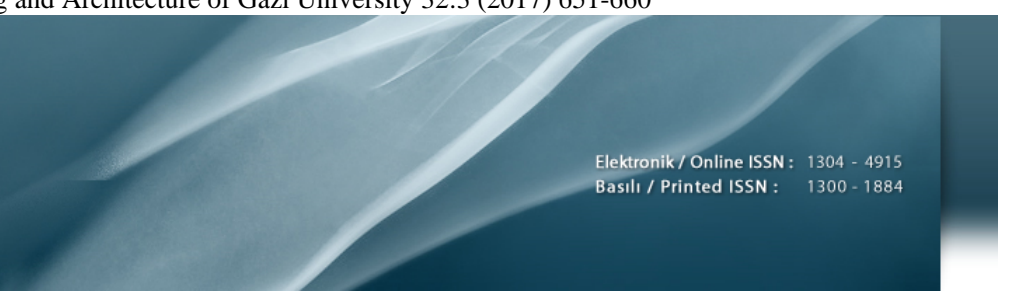

\title{
Ot toplama tırmığı montaj işleminde çalışma duruşlarının anybody modelleme sistemi ile analizi
}

\author{
Demet Gönen ${ }^{*}$ (D) Ali Oral $^{2}$, Can Özcan ${ }^{3}$ \\ ${ }^{1}$ Balıkesir Üniversitesi, Mühendislik Fakültesi Endüstri Mühendisliği Bölümü, Cağış Yerleskesi, Balıkesir, 10145, Türkiye \\ ${ }^{2}$ Balıkesir Üniversitesi, Mühendislik Fakültesi Makine Mühendisliği Bölümü, Çağış Yerleşkesi, Balıkesir, 10145, Türkiye \\ ${ }^{3}$ Akro Mühendislik, GOSB Teknopark, Gebze, Kocaeli, Türkiye
}

Ö N E Ç I K A N L A R

- Montaj hatlarında ergonomik olmayan çalışma duruşları

- Kas iskelet sistemi rahatsızlıkları

- Çalışma duruşlarının Anybody Modelleme Sistemi ile Analizi

Makale Bilgileri

Geliş: 30.06.2016

Kabul: 18.11.2016

DOI:

10.17341/gazimmfd.337613

Anahtar Kelimeler:

Kas iskelet modelleme, biyomekanik simülasyonlar, duruş bozuklukları, bilgisayar destekli ergonomi, anybody modelleme sistemi

\section{ÖZET}

Firmaların ürün kalitelerini arttırmaları ve aynı zamanda ürün maliyetlerini düşürebilmeleri için imalat süreçlerinde sürekli iyileştirme çalışmaları yapmaları gerekmektedir. Ürünün kalitesini ve üretim maliyetini etkileyen unsurlardan en önemlisi çalışanlardır. Çalışanları etkileyen çalışma koşullarının incelenmesi, analiz edilmesi ve değerlendirilmesi, üretim süreçlerinde yapılacak iyileştirmelerde önemli rol oynamaktadır. Çalışma sırasında tekrarlanan ve uzun süreli çalışma duruşları, çalışanın vücudunda çeşitli şiddetlerde zorlanmalara ve zamanla kas iskelet sistemi rahatsızlıklarına (KISR) neden olabilmektedir. KISR, çalışanın performansını ve iş verimini olumsuz etkilemektedir. Çalışma pozisyonları RULA, REBA, NIOSH, OWAS vb. gözlemsel yöntemler ile analiz edilebilmektedir. Bunların yanı sıra insan vücudunu biyomekanik esaslara göre inceleyerek eklem reaksiyon kuvvetlerine göre değerlendirme yapılmasına olanak sağlayan yazılımlarla da analiz yapılabilmektedir. Bu çalışmada, tarım aletleri üreten bir işletmede ot toplama tırmığı montajında görülen duruş bozuklukları, insan vücudunun biyomekanik esaslara göre analizini sağlayan Bilgisayar Destekli Ergonomi (BDE) Yazılımı AnyBody Modelleme Sistemi (AMS) ile incelenmiştir. Yapılan değerlendirme sonucunda çalışma esnasında oluşan duruş bozukluklarını gidermek amacıyla yeni bir montaj ünitesi tasarımı önerilmiştir.

\section{Analysis of working postures in the assembly process of wheel hay rake using anybody modelling system}

\section{H I G H L I G H T S}

- $\quad$ Non-ergonomic work postures in assembly lines

- Musculoskeletal Discomforts

- $\quad$ Analysis of working postures by Anybody Modeling System

Article Info

Received: 30.06.2016

Accepted: 18.11.2016

DOI:

10.17341/gazimmfd.337613

Keywords:

Musculoskeletal modelling, biomechanical simulation, postural disorders, computer aided ergonomics, anybody modelling system

\begin{abstract}
Companies need continuous improvement studies in manufacturing processes to improve the product quality and decrease the costs. The most important factor that affects quality and cost of the product is employee. The investigation, analysis and evaluation of working conditions that affect employees play an important role for improvements to be made in the production processes. Long-term and repeated working postures during the manufacturing activities may cause various severity of strain on employee's body and musculoskeletal disorders (MSDs) in time. MSDs have a negative effect on employee performance and work productivity. Working postures can be analysed using observational methods such as RULA, REBA, NIOSH and OWAS. In addition to these, analysis can also be done using software that allows evaluation considering joint reaction forces by examining the human body according to biomechanical principles. In this study, postural disorders observed in assembly process of wheel hay rake in a company that produces agricultural tools were evaluated using Computer Aided Ergonomics (CAE) software AnyBody Modelling System (AMS) which provides an analysis of the human body according to biomechanical principles. As a result of the evaluation, a new assembly unit design was proposed to remove the postural disorders during the work.
\end{abstract}




\section{GİRIŞ (INTRODUCTION)}

Montaj işlemleri esnasında çalışanlar uzun süre ayakta kalmakta; uzanarak, çömelerek veya eğilerek çalışmaktadırlar. Ergonomik açıdan uygun olmayan bu çalışma duruşları zamanla kas-iskelet sistemi rahatsızlıklarına (KISR) ve üretimin verimsizliğine neden olabilmektedir. Bu rahatsızlıkların oluşmasını önleyebilmek amacıyla çalışma duruşlarının incelenmesi ve değerlendirilmesi için ergonomi biliminden yararlanılmaktadır $[1,2]$. İnsan-makine sistemlerinde insanın kas iskelet sisteminin analizini gerçekleştirerek, insana hasar vermeden uygun bir çalışma ortamı sağlamak amacıyla bilgisayar destekli ergonomi yazılımları da kullanılmaktadır [3]. Endüstride özellikle emek yoğun olarak çalışılan montaj hatlarında biyomekanik yüklenme ve zorlanmaların oluştuğu durumlarda, çalışma duruşlarının iyileştirilmesi amacıyla ergonomik düzenlemeler ya da hattın yeniden tasarımı gerçekleştirilmektedir. Montaj prosesinin iyileştirilmesinde sanal insan modelleri, sanal ortam ve simülasyonların kullanılması faydalı olmaktadır. Mirakhorlo vd. [4], kaldırma işlemlerinde duruş genişliklerinin omurga ve kaslar üzerine etkilerini değerlendirmek üzere kas iskelet modeli geliştirmişlerdir. Kaldırma tekniklerinin (eğilerek, çömelerek vb) kas ve eklemler üzerinde önemli etkileri olduğunu ortaya koymuşlardır. Can vd. [5], elektrik trafoları için metal aksesuar üreten bir firmada, iş istasyonlarında sergilenen çalışma duruşlarını Bulanık REBA Yöntemi ile analiz etmişlerdir. Analiz sonucunda, incelenen duruşlara ilişkin elde edilen tehlike seviyeleri dikkate alınmış ve risk seviyelerini azaltacak iyileştirme önerileri sunulmuştur. Battini vd. [6], montaj tekniği ve ergonomik duruşlar arasındaki ilişkiyi değerlendirmişlerdir. Montaj sistemlerinde tasarım problemleri için eşzamanlı bir mühendislik yaklaşımının uygulanabilirliğini araştırmak için, bir endüstriyel uygulama üzerinde bilgisayar destekli ergonomi yazılımı kullanmışlardır. Chaffin [7], bilgisayar destekli ergonomi yazılımlarında sanal insan modellerinin proaktif ergonomik analiz ve tasarımlar için etkili bir araç olduğunu ve gelecekte çeşitli toplumlar için geliştirilmesi gerektiğini ifade etmiştir. Honglun vd. [8], duruş hareket modelini, iş modelini, insan reaksiyonlarını, karar verme modelini vb. içeren sanal insan modeli oluşturmuşlardır. Geliştirilen sanal insan modeli, sanal prototipleme ve sanal ürün geliştirmede uygulanmıştır. Tripathi vd. [9], bakım işlerinde kas iskelet sistemi rahatsılılılarının, çalışan ile makine arasındaki uyumsuzluktan kaynaklandığını belirtmişlerdir. Hiyerarşik Görev Analizi (HTA), duruş analizi (REBA), biyomekanik modelleme ve sanal insan modellemeyi (DHM) birleștiren bir hibrit metodolojiyi montaj ve bakım faaliyetlerine uygulamışlardır. İş ortamı sanal insan modelleri kullanılarak tekrar tasarlanmış ve çalışanda oluşan zorlanmalar azaltılmıştır. Ergonomik analiz, bu süreçte ürün doğrulama için önemli bir adımdır ve sanal insan bilgisayar destekli ürün ergonomisinde anahtar nokta olmuştur. Çalışanlarda oluşan zorlanmalar RULA, REBA, NIOSH, OWAS vb. gözlemsel yöntemler ile analiz edilebilmektedir. Bu gözlemsel yöntemlerin aksine, insan vücudunun biyomekanik esaslara göre analiz edilmesine yarayan AnyBody Modelleme Sistemi (AMS) ile eklemlerde oluşan zorlanmalar sayısal olarak belirlenmekte, çalışanın iş yaparken harcadığı mekanik enerji ve kas aktivitesi ile yorgunluk üzerinde sayısal karşılaş̧ırmalar yapılabilmektedir. Bir bilgisayar destekli ergonomi yazılımı olan AMS, çeşitli çalışma duruşları ve zorlanmalar için insan vücudunun modellenmesi (Şekil 1) ve insan-makine sistemi ya da insanın çevreyle etkileşimi boyunca kas-iskelet sistemi üzerindeki etkilerini analiz etmek için kullanılabilmektedir [10]. Kas iskelet sistemi simülasyonu, pratik mühendislik uygulamaları ve tıbbi uygulamalar gibi temel araştırmalar için önemli bir konudur. AMS'de modeller kas kuvvetlerinin, eklem reaksiyonlarının, mekanik işin ve verimliliğin, kullanıcı tarafindan belirtilen ölçüler ve tanımlanan hareketler için hesaplanmasını sağlamaktadır. AMS günlük yaşamdaki duruş ve hareketlerin çoğunda, vücudun tüm bölgelerindeki kas iskelet sistemi analizleri için kullanılmaktadır.

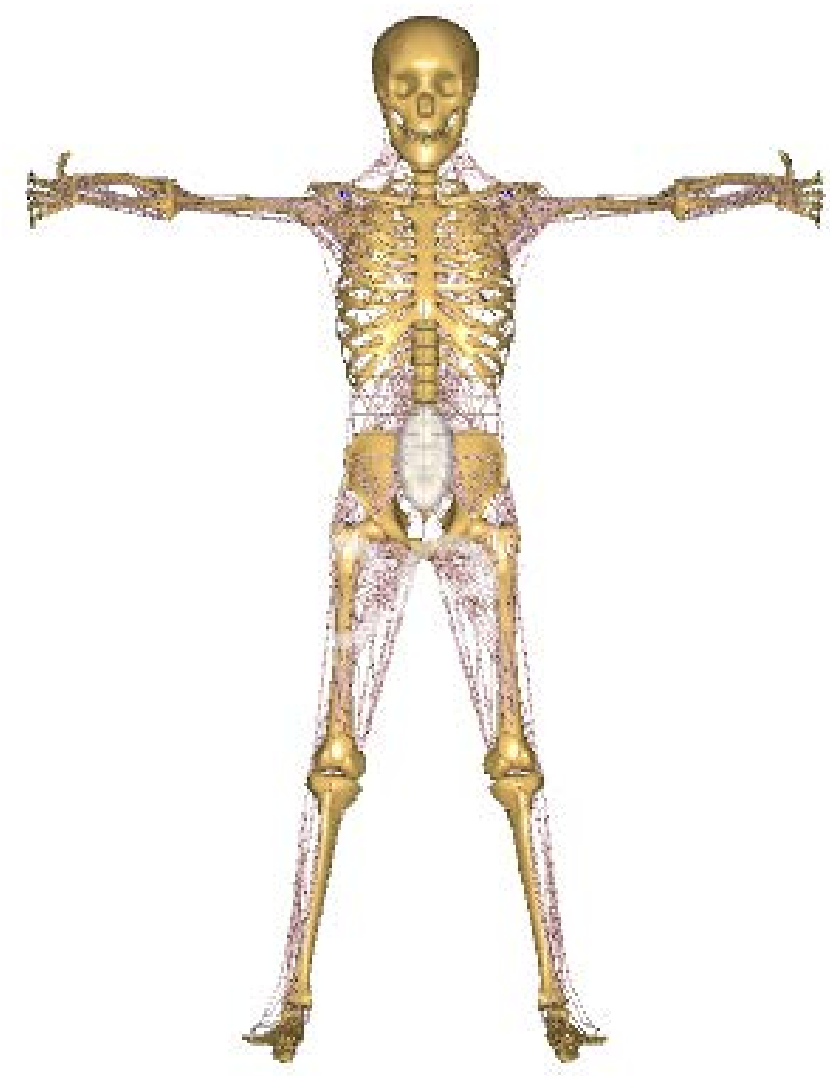

Şekil 1. AMS sanal insan modeli (AMS digital human model)

Cao vd. [11, 12], oturup kalkma, ayakta durma sürecindeki kas kuvvetlerinin belirlenmesi için bir ters dinamik yaklaşımı geliştirmişlerdir. Zemin reaksiyon kuvvetleri, vücudun basınç merkezi, gövde, kalça ve bacakların dönme hareketleri ölçülmüş, aynı zamanda alt ekstremitenin kas kuvvetleri AnyBody Modelleme Sistemi ile hesaplanmıştır. Elde edilen sonuçlar yapılan EMG ölçümleri ile de desteklenmiştir. Oomen vd. [13], yirmi genç ve sağlıklı 
katılımcının antropometrik verilerini toplamışlar ve kişileri ölçeklendirmek için AMS'ye girmişlerdir. Hareket yakalama sistemi ile elde edilen ayak bileği, diz ve kalçanın eklem açıları ile AMS'de gerçekleştirilen analizde ayakla basma hareketi sırasındaki kas aktivasyonları hesaplanmıştır.

Çalışmanın sonucunda genel amaçlar için ölçeklendirmenin yararlı bir araç olabileceği, fakat bireyselleştirilmiş̧ modellemede daha az etkili olduğu belirtilmiştir. Rasmussen vd. [14], detaylı bir kas iskelet modeli kullanarak vinç çalıştıran bir denizcinin üst gövdesinin hareketlerini hesaplamak için ters-ters dinamik tekniğini uygulamışlardır. Denizcinin modeli AMS'de geliştirilmiş, omurga fleksiyon veya ekstansiyonu, yanal fleksiyon, sağ ön kolun pronasyon veya supinasyonu gibi toplamda 18 değişken parametrelerle ifade edilmiştir.

Rasmussen vd. [15], ergonomik tasarım için ileri kas iskelet simülasyonu tabanlı yeni imkanlardan bahsettikleri çalışmalarında, AMS'de el testeresiyle kesme işlemi için bir analiz gerçekleştirmişlerdir. $\mathrm{Bu}$ analiz sonucunda ise testerenin tutuşu için ürün tasarımını geliştirmek amacıyla kullanılabilecek kas kuvvetleriyle ilgili veriler elde etmişlerdir. Gönen vd. [16], altı köşe başlı cıvata ile montajı gerçekleştirilen bir ot toplama tırmığı montajı için klasik REBA analizleri ve CATIA Ergonomi modülü ile RULA analizleri gerçekleştirmiştir. Montaj işleminde, bir çalışan çömelerek somunları anahtar ile tutmakta diğer çalışan hava tabancası ile altı köşe başlı cıvataları sıkmaktadır. Çalışmada, somunun anahtar ile tutulması yerine üzerine somunların yerleştirildiği bir sac plaka kullanılarak çömelerek çalışan işgörenin görevinin ortadan kaldırılması sağlanmıştır. Çalışma sonunda, yapılan önerilerin uygulanmasıyla işlem süresinin yaklaşı $\% 60$ azaltılması sağlanmıştır.

Bu çalışmada, tarım aletleri üreten bir işletmenin ürün gamı içerisinde yer alan, yuvarlak başlı kasa cıvatası ile birleştirilen ot toplama tırmığının yıldız çarkı montaj sürecindeki uygun olmayan duruş duruşlarının iyileştirilmesi amaçlanmıştır. Montaj işleminde çalışanlar üzerinde oluşan zorlanmalar ve kas aktivasyonlarını belirlemek için analizler yapılmıştır. Gönen vd. [16] çalışmasından farklı olarak bu çalışmada; çalışma duruşlarının analizleri, tek bir risk faktör değer çıktısı alabilen RULA ve REBA yöntemlerinin yerine; eklemlerdeki yük değerlerini sayısal olarak hesaplayabilen AMS ile gerçekleştirilmiştir.

\section{OT TOPLAMA TIRMIĞI YILDIZ ÇARKI MONTAJI} (ASSEMBLY OF HAY RAKE WHEEL)

Ot Toplama Tırmığı; biçilen ürünün yayılması, alt-üst edilmesi ve tekrar toplanmasında kullanılan, 4 adet y1ldız çarktan oluşan bir tarım aletidir (Şekil 2). Çalışmanın gerçekleştirildiği işletmede ot toplama tırmı ğı yıldız çarkının yuvarlak başlı kasa cıvatası ile montajı esnasında işgörenin çalışma pozisyonları incelenmiştir.

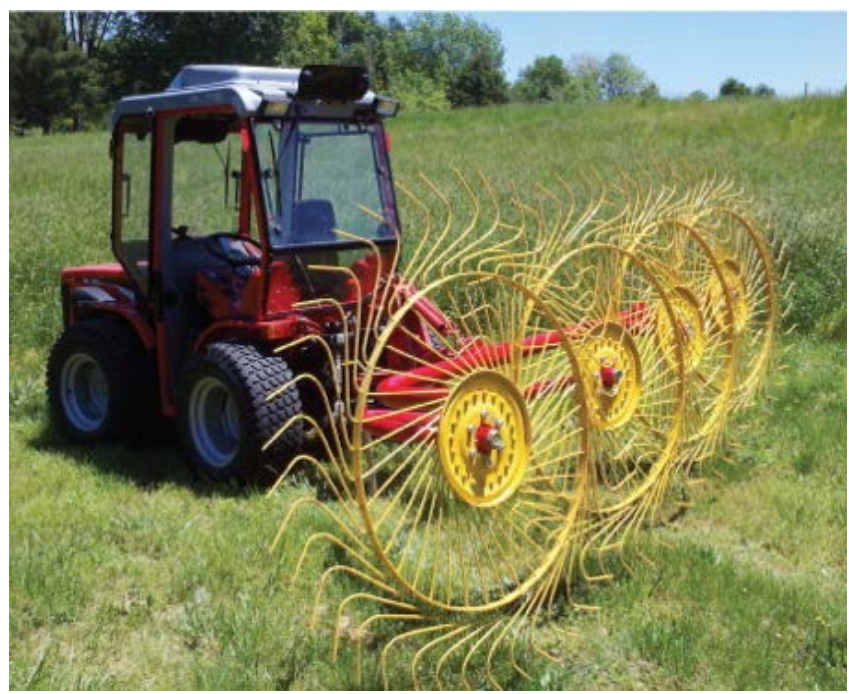

Şekil 2. Ot toplama tırmığı [17] (Hay rake)

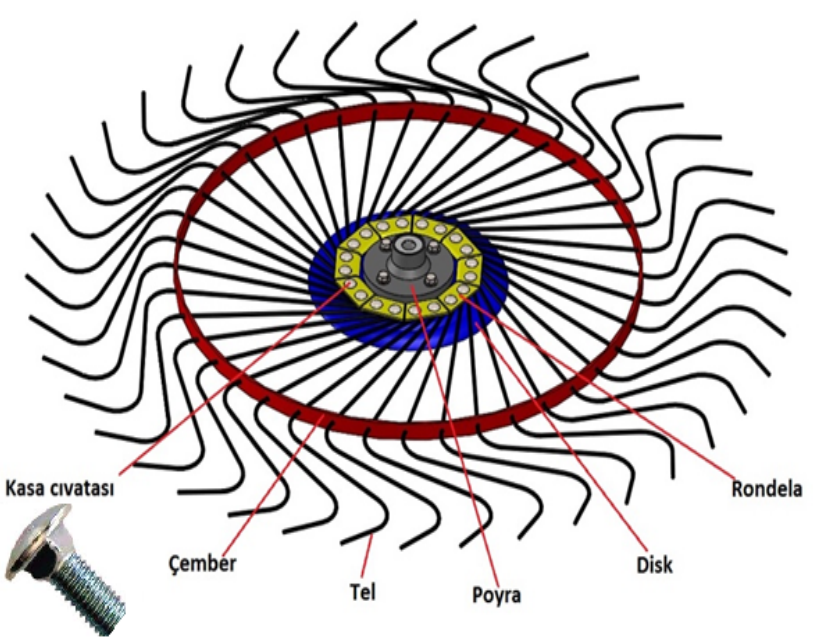

Şekil 3. Ot toplama tırmığı- yıldız çarkı 3D görünüş (Wheel hay rake - 3D view)

Yıldız çarkı oluşturulurken teller, bir çemberin içinden geçirilmekte ve çarkın merkezindeki disk üzerine yerleştirilmektedir (Şekil 3).Telleri diske sabitlemek için üzerlerine rondelalar ve kasa cıvataları yerleştirilmekte ve sehpanın alt kısmından cıvatalara el ile somun takılmaktadır. Tellerin disk üzerine ön yerleştirilmesi yapıldıktan sonra kasa cıvatalarının üzerine (cıvatanın sıkma sırasında eksenel doğrultudaki hareketini engellemek için) $12 \mathrm{~kg}$ ağırlık konularak somunlar hava tabancasiyla sıkılmaktadır. Civata sıkma işlemi için çalışan montaj sehpasının altına çömelerek işlem yapmaktadır (Şekil 4a-e) [18]. Montaj sırasında çalışanlar çömelerek, uzanarak ve eğilerek iş yapmaktadır (Şekil 4). Yıldız çarkının oluşturulması sırasında uygun olmayan iki çalışma duruşu görülmektedir. Birinci uygun olmayan çalışma duruşunda; somunların sıkılması işleminde kasa cıvatalarının hareketini engellemek için bu cıvataların üzerine kütle konulmaktadır. Bu işlemde çalışan elindeki kütleyi, öne doğru uzanarak kasa cıvatalarının üzerine bırakmaktadır (Şekil 4c). Bu işlem nedeniyle çalışan, 
özellikle bel ve bacak ağrılarından şikâyet etmektedir. İkinci uygun olmayan çalışma duruşu ise, montaj sehpasının altında somunları sıkma işlemini yapan çalışanın çömelme duruşudur (Şekil 4d-e). Bu çalışma pozisyonunda, çalışanın bacaklarında, belinde, sırtında, boynunda ve ayak bileklerinde zorlanmalar oluşmaktadır. Öncelikle çalışanlar tarafından çalışmanın doğasında olduğu kabul edilen ve sorun olarak görülmeyen bu zorlanmalar zaman geçtikçe KİSR oluşturmaktadır.

\section{AMS İLE DURUŞ ANALIZLERİ (POSTURE ANALYSIS USING AMS)}

Yıldız çarkı montajı esnasında işgörenin çalışma duruşları AMS ile analiz edilmiştir. Öncelikle $12 \mathrm{~kg}$ kütleye sahip ağırlığın yuvarlak başlı kasa cıvatalarının üstüne konulması aşaması modellenmiştir (Şekil 5). Şekil 4c 'de görüldüğü gibi çalışan çemberin dışına çıkan tellerin uzantısından dolayı montaj sehpasına çok fazla yaklaşamamaktadır. Bu nedenle çalışan öne eğilerek iki eliyle tuttuğu kütleyi kasa cıvatalarının üzerine bırakmaktadır.

Bu çalışma durumunda çalışanın bacak, bel ve omuzunda zorlanmalar oluşmaktadır. Görülen zorlanmaların azaltılması amacıyla ağırlığın kasa cıvatalarının üzerine yerleştirilmesini kolaylaştıracak bir çözüm önerilmiştir. Önerilen çözümde, somunların hava tabancası ile sıkılması esnasında kasa cıvatalarının yerinden çıkmaması için montaj ünitesi üzerine konulan kütle üzerine Şekil 6'da görüldüğü gibi tutma kolları eklenmiştir. $\mathrm{Bu}$ kollar yardımıyla, bu kütlenin yerine konması sırasında çalışanın belini daha az zorlayacak bir çalışma ortamı oluşturulması amaçlanmıştır. Şekil 7'de önerilen durum için oluşturulan sanal insan ve montaj işlemi modeli verilmiştir. Şekil 8'de ağırlığın yerleştirilmesi sırasında mevcut durum ve önerilen durum için çalışanın eklemlerine gelen reaksiyon kuvvetleri karşılaştırılmıştır. Yeni ağırlık tasarımı kullanıldığında mevcut duruma göre özellikle bel bölgesi eklemlerinde oluşan reaksiyon kuvvetlerinde azalma olduğu görülmüştür. Aparatlı tasarımda, bel bölgesi eklemlerindeki zorlanmaların azalma oranları Şekil 8'de görülmektedir. Şekilde mevcut durumda bel ve omuz bölgesindeki eklem kuvvetleri yüksek iken, Şekil 9'da yeni ağırlık tasarımın kullanılması halinde kollar üzerindeki kuvvetleri yüksek olmaktadır. Omuz-Kol bölgesindeki eklemler için reaksiyon kuvvetleri karşılaştırıldığında, yeni ağırlık tasarımında, dirsek ve bilek bölgelerinde, mevcut duruma göre eklem kuvvetlerinin arttığı, omuz eklemlerindeki eklem kuvvetlerinin azaldığı görülmektedir.

Şekil 10'da mevcut durum ve önerilen durum için bacak bölgesindeki eklem reaksiyon kuvvetleri ve yeni tasarımda eklem reaksiyonlarında meydana gelen azalma oranları görülmektedir. Her iki çalışma durumu değerlendirildiğinde, mevcut durumda kalça, diz ve ayak bileklerine daha çok yükleme olduğu görülmüştür.Gövde, omuz-kol ve bacak bölgeleri için eklem kuvvetleri, momentleri ve kas aktivasyon aralıkları ayrı ayrı incelenerek karşılaştırma yapılmıştır. Burada; eklem kuvveti, farklı kemiklerin 654 birleşme noktalarından geçen kuvvet değeri olarak tanımlanırken; eklem momenti, eklemin ne kadar yüklendiğini ifade etmektedir. Kas aktivasyon seviyeleri yorulma ile direkt ilişkilendirilebilen bir veri olduğu için çalışanın yorulması ve verimi hakkında bilgi edinilmesi amacı ile kullanılabilmektedir [19]. Kas aktivasyon seviyeleri karşılaştırıldığında, mevcut durum ve aparatlı tasarımın bel bölgesi kaslarındaki farklı yükleme durumları görülebilir (Şekil 11).

Ot toplama tırmığı yıldız çarkının montajı esnasında, ağırlığın montaj sehpasının üzerine yerleştirilmesinden sonra çalışan cıvataları sıkmak için montaj sehpasının altına çömelmekte ve somun sıkma işlemini basınçlı hava tabancası ile gerçekleştirmektedir. Basınçlı hava tabancasıyla somun sıkma işleminde, tabancadan gelen moment yükü sanal insan modelinin sağ eli üzerine uygulanmıştır [18].

$\mathrm{Bu}$ çalışma durumunda, uzun süre çalışılması halinde çalışanın bacak, bel, boyun ve kol kaslarında zorlanmalar oluşmaktadır. Çalışmada, montaj sisteminin $90^{\circ}$ çevrilerek baş üstü çalışmadan kaçınmaya yönelik değerlendirmeler yapılmıştır. Ancak, yıldız çarkını oluşturan tellerin yere dökülmesini engelleyecek bir yapı kurulamamıştır. Bu nedenle çalışmada baş üstü çalışma, kaçınılamayan durum olarak değerlendirilmiştir. $\mathrm{Bu}$ çalışma durumunun iyileştirilmesi için tellerin disk üzerine yerleştirilmesini takiben montaj sehpasının Şekil 13'de görüldüğü gibi çalışanın boyuna göre yükseltilmesinin uygun olacağı değerlendirilmiştir. Montaj sehpasının işletmede kullanıldığ mevcut durumda ve Şekil 13 'te görüldüğü gibi düzenlenmesi halinde gerçekleştirilen çalışmada gövde reaksiyon kuvvetleri AMS ile analiz edilmiştir. Her iki durum için analiz sonuçları Şekil 14'te verilmiştir. Şekil incelendiğinde çömelerek çalışma durumunda eklemlere daha fazla yük etki ettiği ve iyileştirilen montaj sisteminde eklemlere daha düşük yük geldiği görülmektedir.

Mevcut ve önerilen durum için omuz-kol bölgesindeki eklem kuvvetleri incelendiğinde yine çömelerek çalışma durumunda daha büyük reaksiyon kuvvetleri oluştuğu görülmüştür (Şekil 15). Şekil incelendiğinde, ayakta montaj yapılması durumunda bilek ve dirsek eklemlerinde daha az yükleme oluştuğu ancak omuz ekleminde \%33 daha fazla yükleme oluştuğu görülmektedir. Sol ve sağ bacak bölgesindeki eklem kuvvetleri mevcut ve önerilen durum için karşılaştırıldığında, Şekil 16a ve Şekil 16b'de çömelerek çalışma durumunda eklem yüklerinin daha yüksek olduğu görülmüştür. Örneğin; değerlendirme sonuçlarına göre sağ bacakta ayakta çalışma halinde, çömelerek çalışmaya göre kalça eklemine \%76, bilek eklemine \%89 daha az kuvvet etki etmektedir.

Montaj işlemi esnasında mevcut durum ve önerilen çalışma durumu için gövde, omuz-kol ve bacak bölgesindeki kas zorlanmaları karşılaştırıldığında; önerilen iyileştirme doğrultusunda kas zorlanmalarında önemli ölçüde azalma olduğu gözlenmiştir (Şekil 17). 


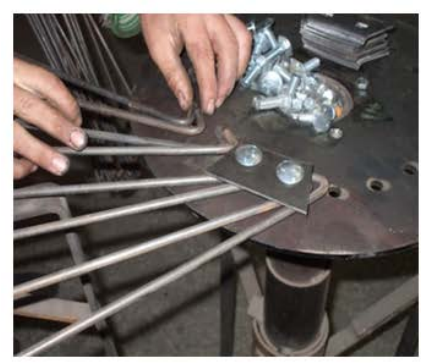

a)

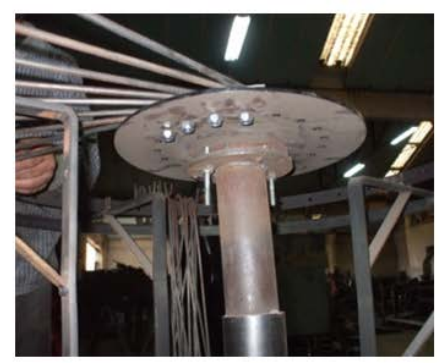

b)

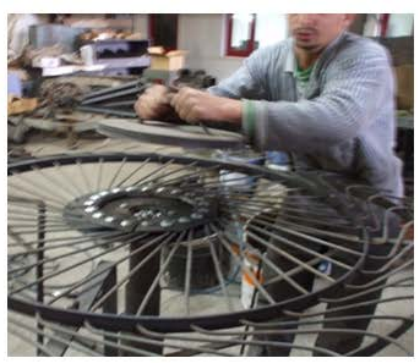

c)

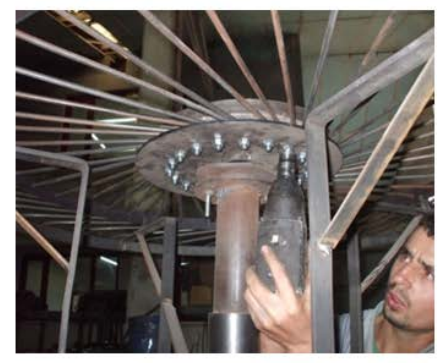

d)

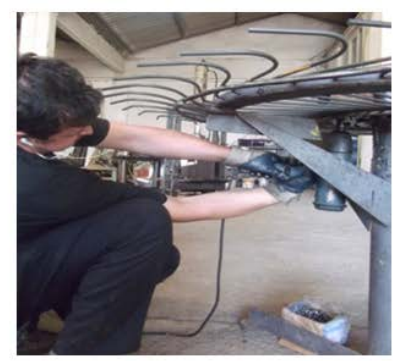

e)

Şekil 4. Yıldız çarkının montaj işlemi (The assembly process of wheel rake)
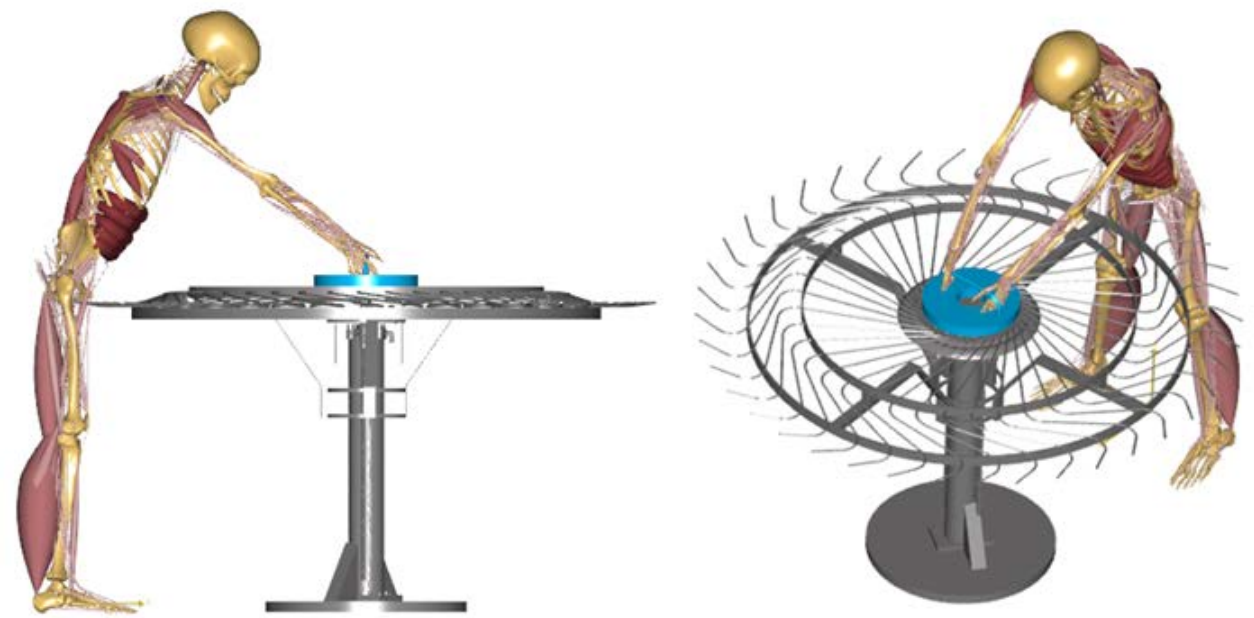

Şekil 5. Ağırlı̆̆ın montaj sehpası üzerine yerleştirilmesi (Placing the load on assembly table)

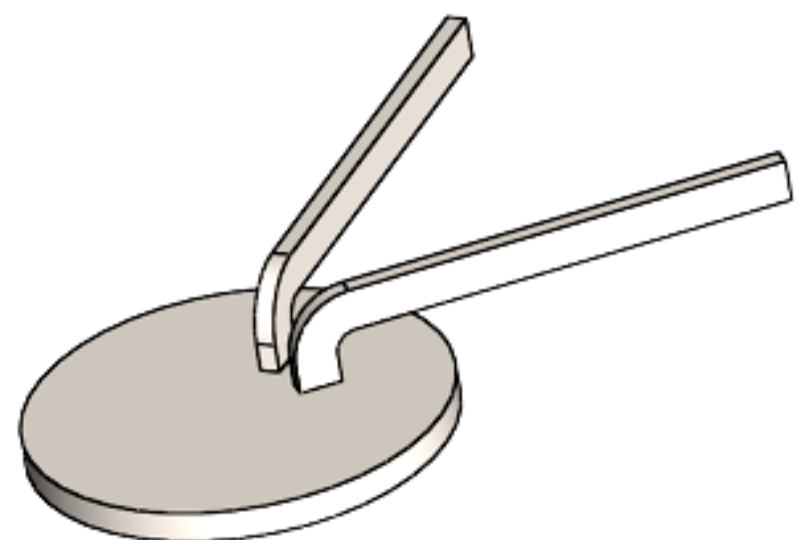

Şekil 6. Tutma kolu eklenmiş ağırlık (Handle added load) 

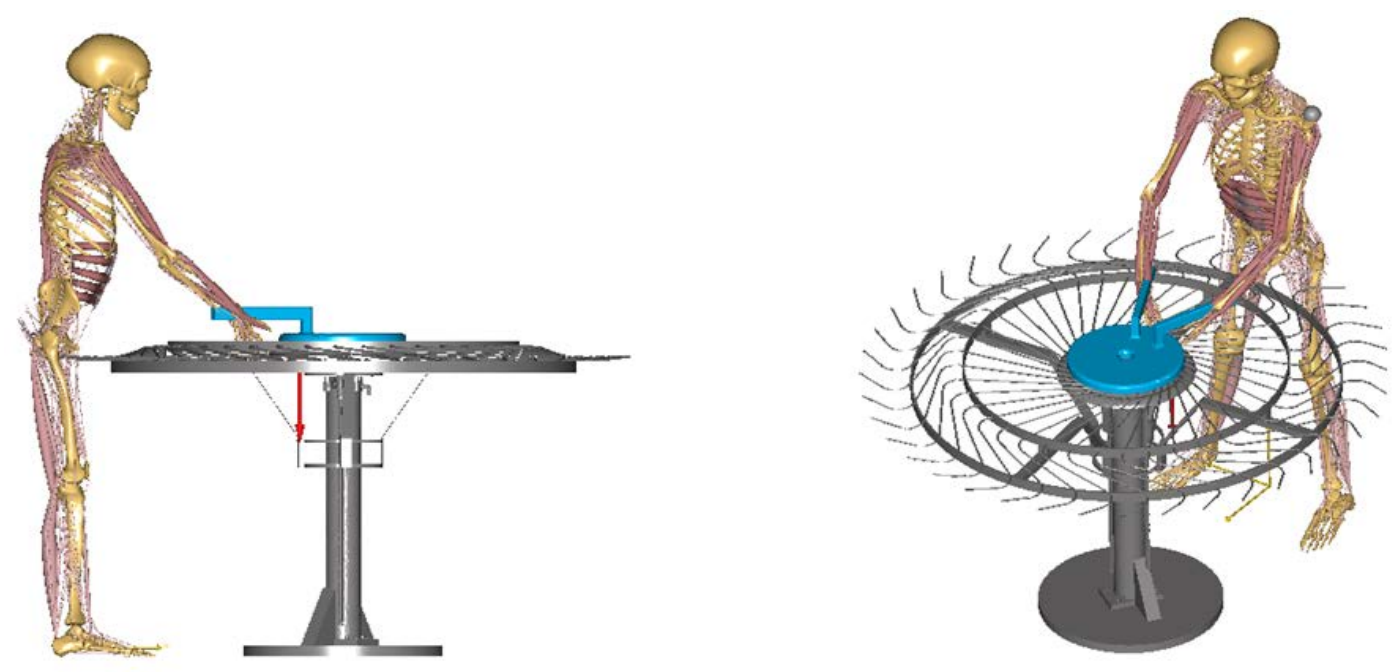

Şekil 7. Tutma kolu eklenmiş ağırlığın montaj sehpası üzerine yerleştirilmesi (Placing the handle added load on assembly table)

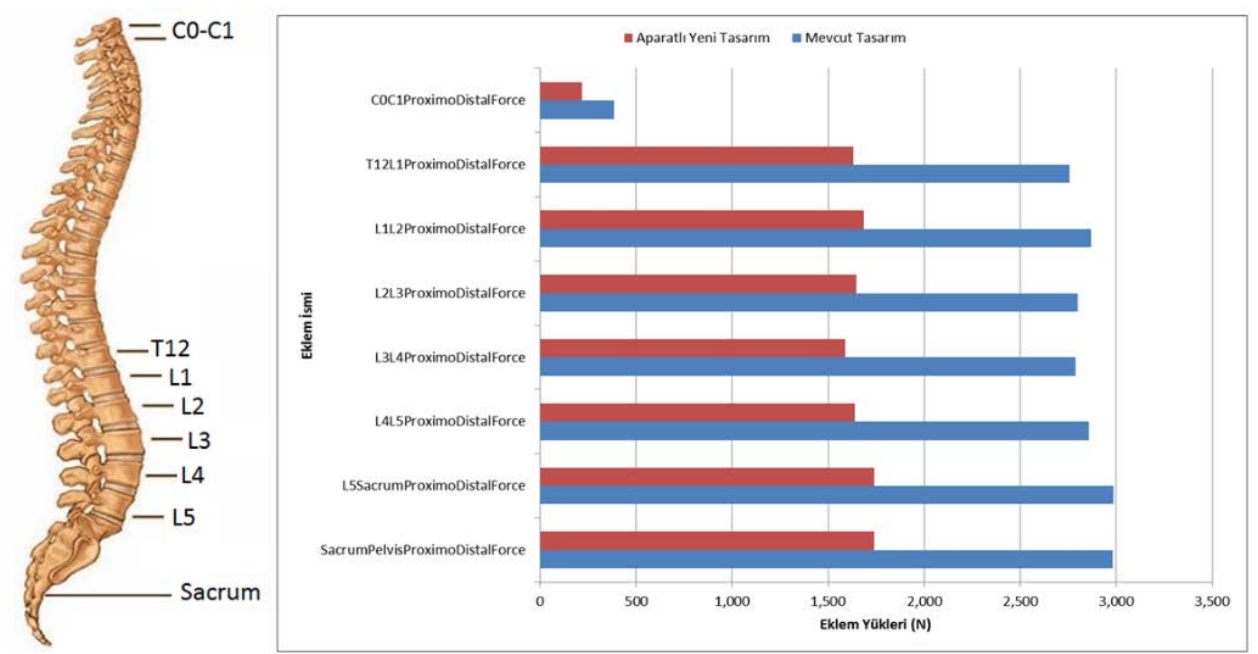

Şekil 8. Gövde içerisindeki bağlantılar için reaksiyon kuvvetleri (Reaction forces for the joints in the body)

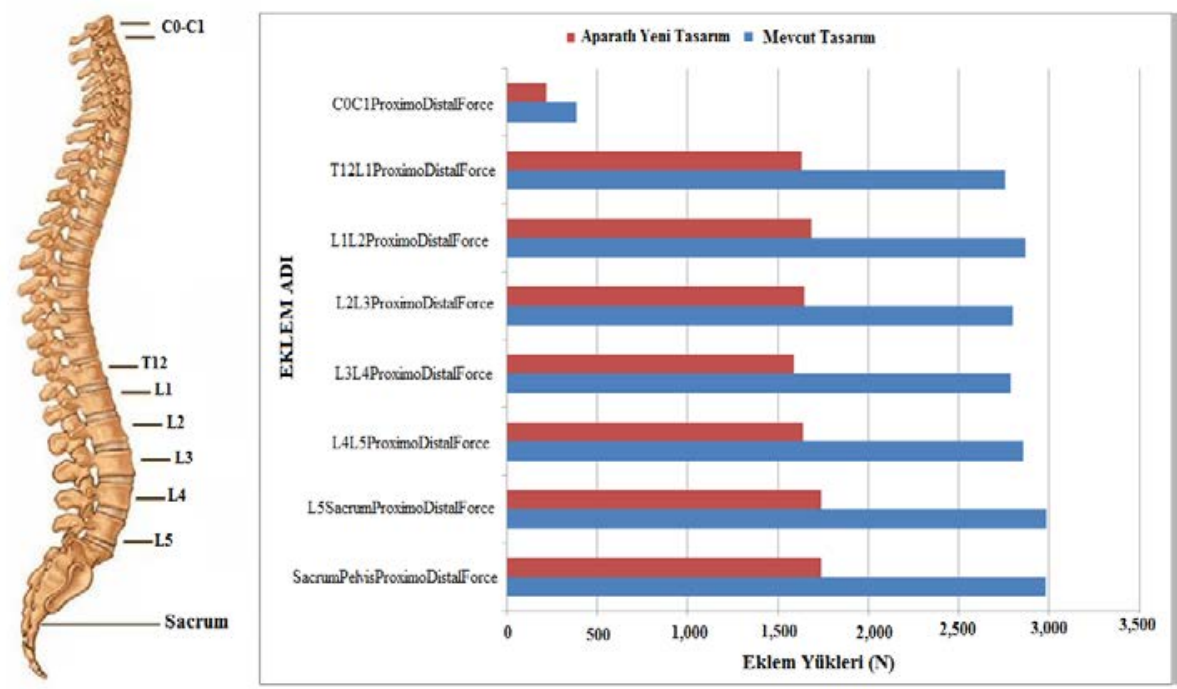

Şekil 9. Omuz-Kol bölgesindeki bağlantılar için reaksiyon kuvvetleri (Reactions forces for the joints in shoulder-arm region) 


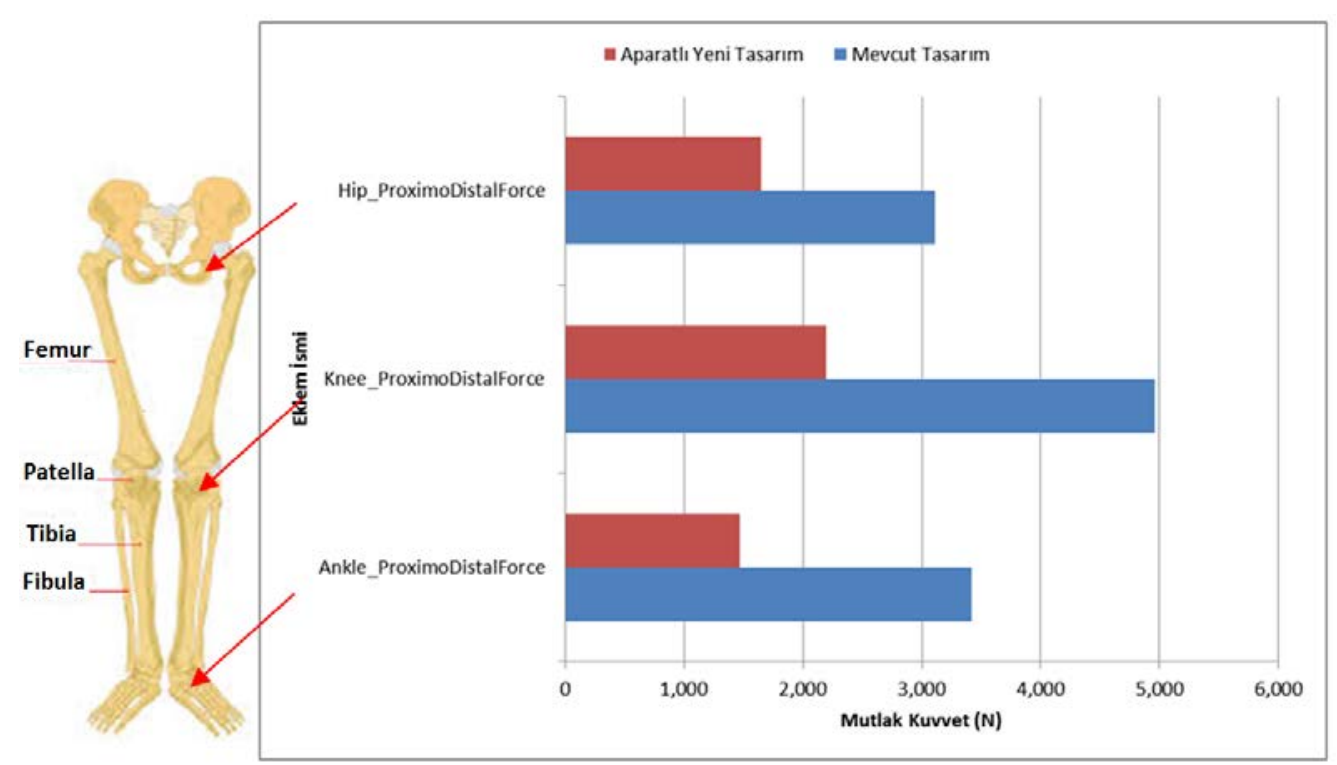

Şekil 10. Bacak bölgesindeki bağlantılar için reaksiyon kuvvetleri (Reactions forces for the joints in leg region)

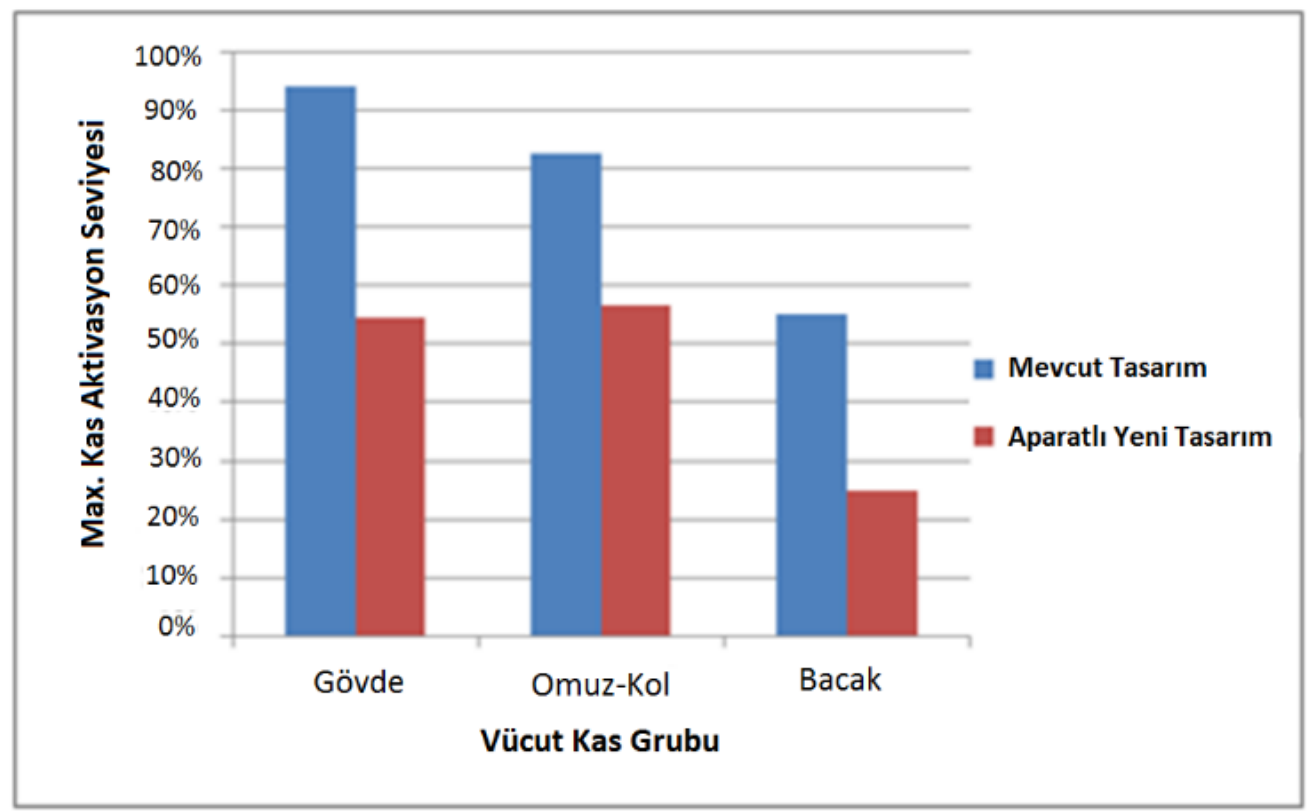

Şekil 11. Mevcut durum ile önerilen durum için kas aktivasyon seviyelerinin karşılaştırılması (Comparison of the muscle activation levels of current and proposed situations)
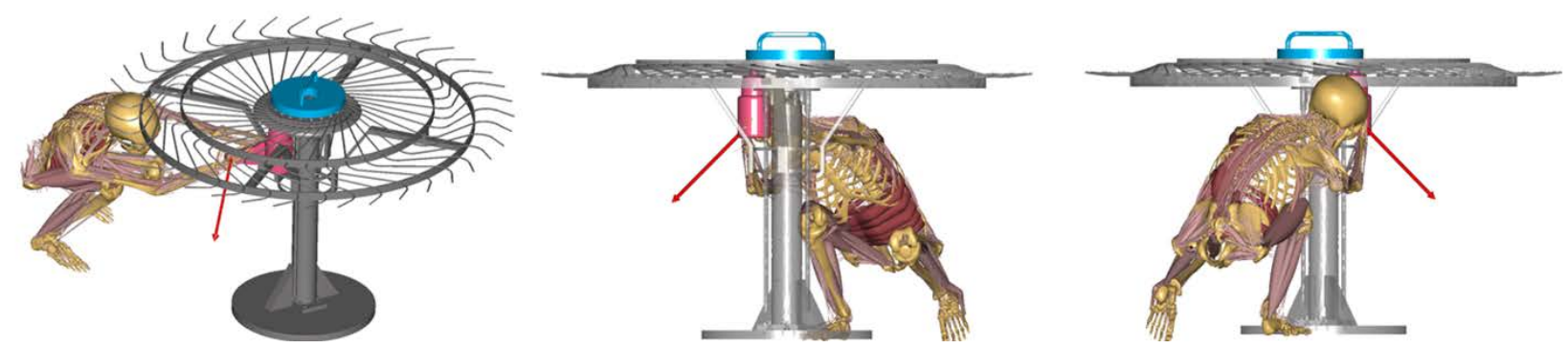

Şekil 12. Çömelerek basınçlı hava tabancasıyla cıvata sıkma işlemi (Screw tightening process using compressed air gun and squatting) 

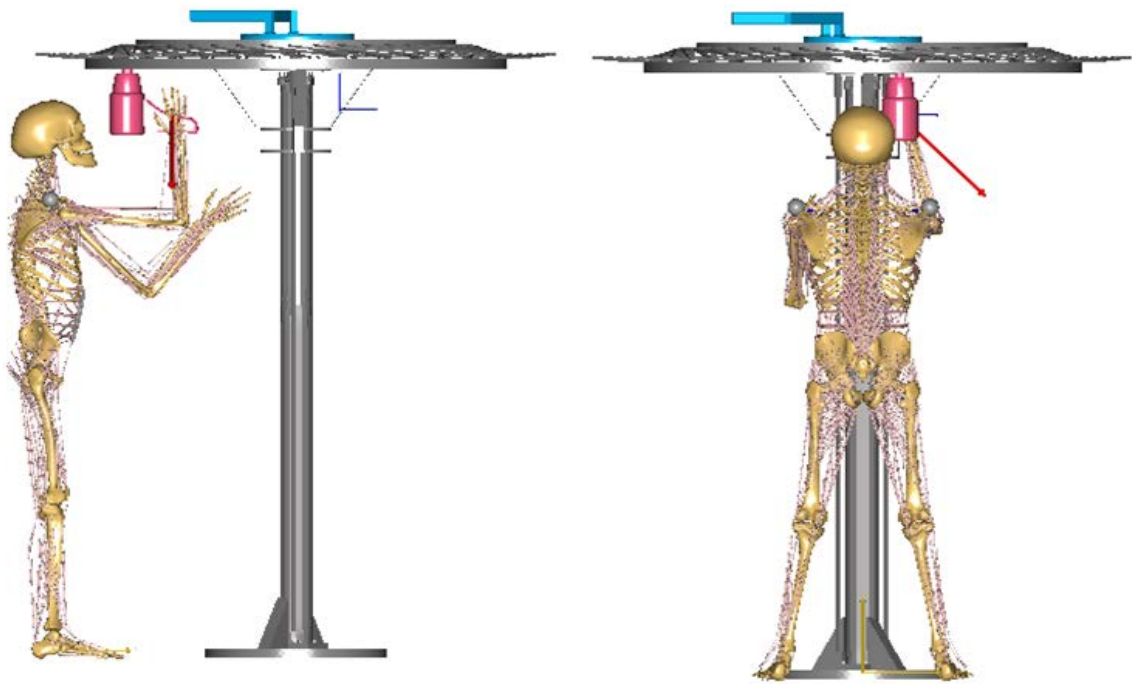

Şekil 13. Cıvata sıkma işlemi için önerilen çalışma duruşu (Proposed working posture for screw tightening process)
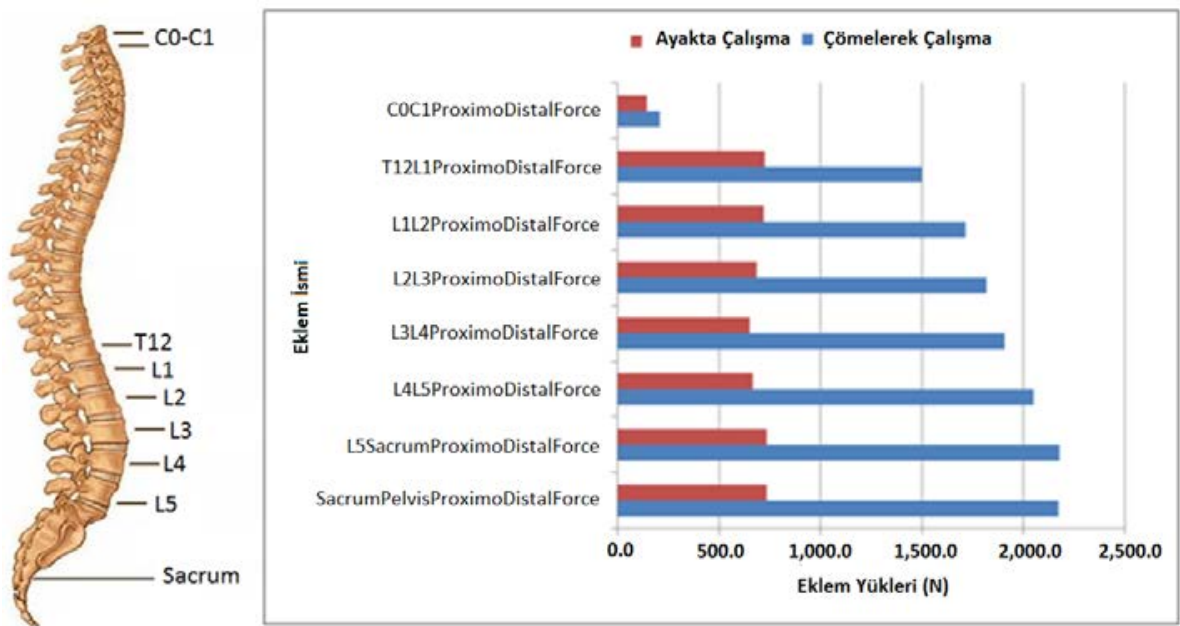

Şekil 14. Gövde içerisindeki bağlantılar için reaksiyon kuvvetleri (Reaction forces for the joints in the body)

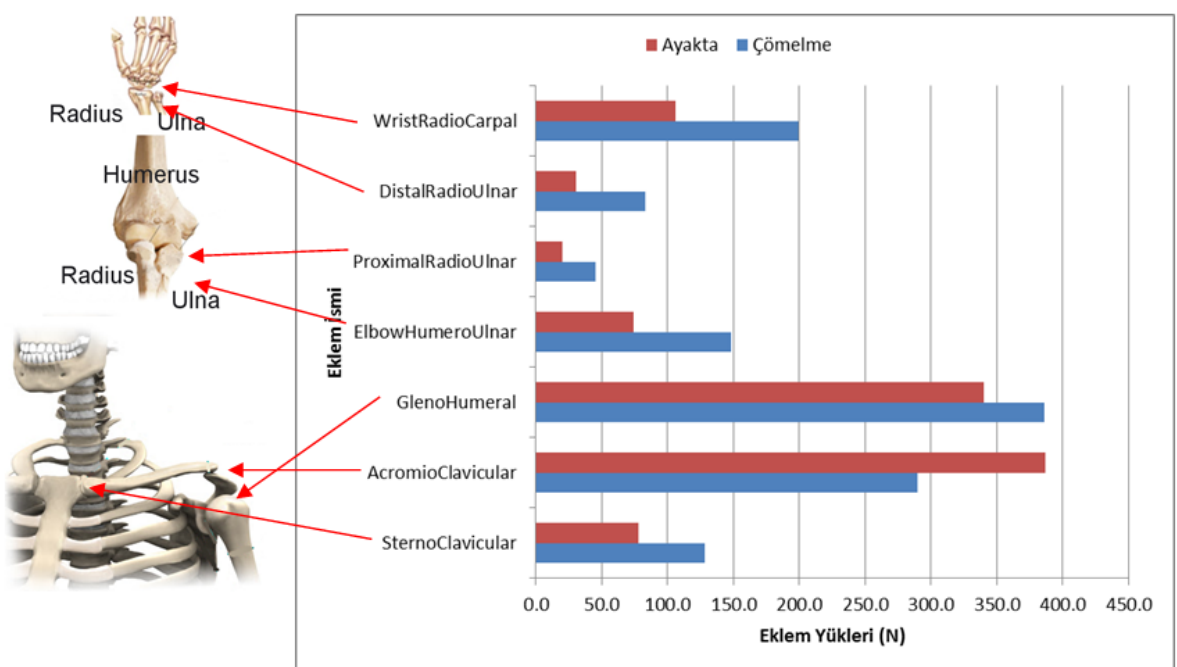

Şekil 15. Omuz-Kol bölgesindeki bağlantılar için reaksiyon-(Sağ Kol) (Reactions forces for the joints in shoulder-arm region (right arm)) 


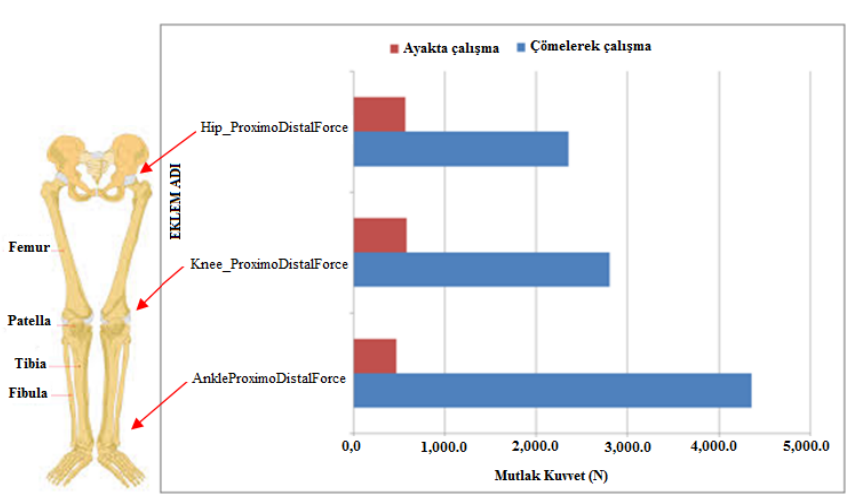

(a)

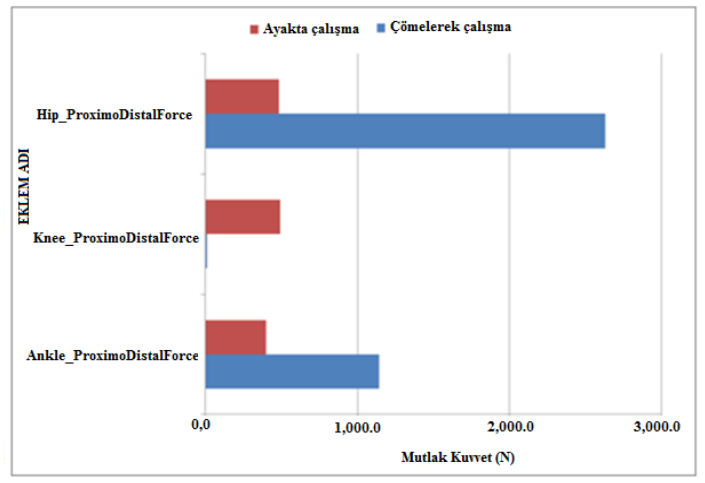

(b)

Şekil 16. Bacak bölgesindeki bağlantılar için reaksiyon kuvvetleri (Reactions forces for the joints in leg region)

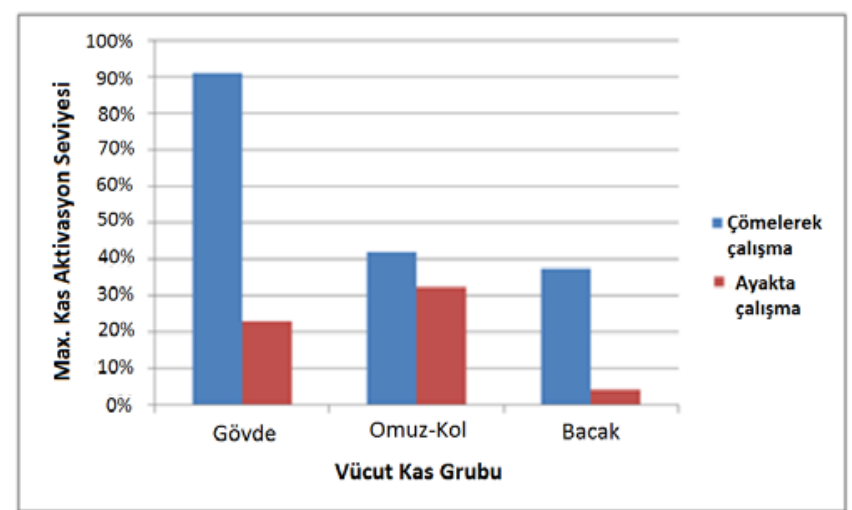

Şekil 17. Mevcut durum ile önerilen durum için kas aktivasyon seviyelerinin karşılaştırılması (Comparison of the muscle activation levels of current and proposed situations)

\section{SONUÇLAR VE TARTIŞMAR (RESULTS AND DISCUSSIONS)}

Çalışmada, ot toplama tırmığına ait yıldız çarkının montajı esnasında çalışanların çalışma duruşları incelenmiş ve ergonomik açıdan uygun olmayan çalışma duruşlarının çalışanları zorladığı görülmüştür. Bu çalışma duruşlarını ve çalışanlar üzerindeki zorlanmaları niceliksel olarak tespit etmek için kas-iskelet sistemi analizleri AMS ile gerçekleştirilmiştir. Gerçekleştirilen analizler sonucunda, eklem reaksiyon kuvvetleri ve kas aktivasyon seviyeleri belirlenmiş ve ergonomik olmayan mevcut çalışma koşullarında işgörenlerde zorlanmaların fazla olduğu görülmüştür. $\mathrm{Bu}$ zorlanmalar çalışanın erken yorulmasına neden olmakta ve çalışma performansını olumsuz etkilemektedir. Ergonomik açıdan uygun olmayan ve çalışanı zorlayan bu çalışma duruşlarını gidererek konforlu bir çalışma ortamı oluşturmak ve iş verimini arttırabilmek amacıyla yeni montaj birimi tasarımı için öneriler sunulmuştur. Önerilen tasarım için AMS analizleri tekrarlanmıştır. Gövde ve bacak eklemleri için reaksiyon kuvvet değerlerinin azaldığı görülmüştür. Ancak tüm eklemler için reaksiyon kuvvet değerlerinin azaltılması başarılamamış, bazı eklemlerdeki kuvvet değerlerinde artışlar gözlemlenmiştir. Özellikle kol-omuz bölgesinde artış gösteren eklem reaksiyon kuvvet değerlerinin artışı, kaçınılamayan durum olarak değerlendirilmiştir. Çalışmanın devamında; el ve kol postür tanımlamalarının hassasiyetinin hareket yakalama sistemi veya gonyometre ölçümleri ile iyileştirilebileceği düşünüldüğünden, insan modeline ait çalışma duruşunun hareket yakalama sistemiyle elde edilmesine yönelik çalışmalar yapılması önerilmektedir. Ayrıca, çalışmanın yapıldı̆̆ı işletme tarafından önerilen iyileştirmelerin gerçekleştirilmesi ve bunun sonucunda zaman etütlerinin yapılması, çalışanların işle ilgili şikayetlerinin tekrar değerlendirilmesi öncelikle önerilmektedir.

\section{KAYNAKLAR (REFERENCES)}

1. Güner B., Hasgül S., Montaj İşçilerinde Görülen Fiziksel Rahatsızlıklar ve Risk Faktörleri Üzerine Bir Çalışma, 17. Ulusal Ergonomi Kongresi, Eskişehir, Türkiye, 493-502, 14-16 Ekim ,2011.

2. Akay D., Kurt M., Dağdeviren M., Ergonomic Analysis of Working Postures. Journal of the Faculty of Engineering and Architecture of Gazi University, 18 (3), 73-84, 2003.

3. http://en.wikipedia.org/wiki/Computer_aided_ergonom ics, Erişim Tarihi 02.10.2011.

4. Mirakhorlo M., Azghani M.R., \& Kahrizi S., Validation of a musculoskeletal model of lifting and its application for biomechanical evaluation of lifting techniques. Journal of Research in Health Sciences, 14 (1), 23-28, 2013. 
5. Can G.F., Atalay K.D., Eraslan E., Working Posture Analysis in Fuzzy Environment and Ergonomic Work Station Design Recommendations, Journal of the Faculty of Engineering and Architecture of Gazi University, 30 (3), 451-460, 2015.

6. Battini D., Faccio M., Persona A., Sgarbossa F., New methodological framework to improve productivity and ergonomics in assembly system design. International Journal of Industrial Ergonomics (Int. J. Ind. Ergon.), 41 (1), 30-42, 2011.

7. Chaffin D.B., Human motion simulation for vehicle and workplace design, Human Factors and Ergonomics in Manufacturing (Hum. Factors Ergon. Manuf. Serv. Ind.), 17 (5), 475-484, 2007, Published online in Wiley InterScience (www.interscience.wiley.com). DOI: 10.1002/hfm.20087, 2007.

8. Honglun H., Shouqian S., Yunhe P., Research on virtual human in ergonomic simulation. Computers \&Industrial Engineering (Comput. Ind. Eng.), 53 (2), 350-356, 2007.

9. Tripathi B., Rajesh R., Maiti J., Ergonomic evaluation of billet mould maintenance using hierarchical task analysis, biomechanical modeling and digital human modeling. Computer-Aided Design and Applications, 12 (3), 256-269, 2014.

10. Damsgaard M., Tørholm Christensen, S. \& Rasmussen, J., An efficient numerical algorithm for solving the muscle recruitment problem in inverse dynamics simulations, International Society of Biomechanics, XVIIIth Congress, Zurich, Switzerland, 3, July 8-13, 2001.

11. Cao E., Inoue Y., Liu T., Shibata K., Estimation of lower limb muscle forces during human sit-to-stand process with a rehabilitation training system. IEEE-EMBS International Conference on Biomedical and Health
Informatics (BHI), Hong Kong, China, 1016-1019, 2012.

12. Cao E., Inoue Y., Liu T., Shibata K., An inverse dynamic approach for quantitative muscle force estimation during human standing-up process. Journal of Biomechanical Science and Engineering, 8 (1), 6378, 2013.

13. Oomen P.W., Drost M.R., van Rhijn L.W., Meijer K., Is strength scaling sufficient for the development of personalized multibody models? 20th Annual Symposium on Computational Methods in Orthopaedic Biomechanics, California, ABD, 2012.

14. Rasmussen J., Challenges in human body mechanics simulation. Procedia IUTAM, 2, 176-185, 2011.

15. Rasmussen J., Boocock M., Paul G., Advanced musculoskeletal simulation as an ergonomic design method. Work: A Journal of Prevention, Assessment and Rehabilitation, 41, 6107-6111, 2012.

16. Gönen D., Oral A., Yosunlukaya M., Computer-Aided Ergonomic Analysis for Assembly Unit of an Agricultural Device, Human Factors and Ergonomics in Manufacturing \& Service Industries, 26 (5) 615-626, 2016.

17. A\&R Engineering. Hay rake. http://www.areng.com. au/hay-gear. Erişim Tarihi Şubat 03, 2016.

18. Gönen D., Oral A., Bir Tarım Aleti Montaj Ünitesinin Bilgisayar Destekli Ergonomik Analizi, 18. Ulusal Ergonomi Kongresi, 16-18 Kasım, Gaziantep, Türkiye, 2012.

19. Whiting W.C., Zernicke R.F., Biomechanics of musculoskeletal injury. Human Kinetics Europe Ltd., 2008. 